\title{
Skin temperature response to unilateral training measured with infrared thermography
}

\author{
Víctor L. Escamilla-Galindo', Alejandro Estal-Martínez ${ }^{1,2}$, Jakub G. Adamczyk ${ }^{3}$, Ciro José Brito ${ }^{4, *}$, Javier Arnaiz-Lastras ${ }^{1}$, \\ Manuel Sillero-Quintana' \\ 'Physical Activity Laboratory, Department of Sports, Faculty of Physical Activity and Sport Sciences, Technic University of Madrid, Madrid, Spain \\ 'University Centre of Health Sciences San Rafael-Nebrija, Faculty of Physiotherapy, Antonio de Nebrija University, Madrid, Spain \\ ${ }^{3}$ Theory of Sport Department, Faculty of Physical Education, University of Physical Education, Warsaw, Poland \\ ${ }^{4}$ Department of Physical Education, Federal University of Juiz de Fora, Governador Valadares, Brazil
}

This study aimed to identify the skin temperature (Tsk) behavior to understand the acute cross-effect after unilateral training of lower-limbs. Seventeen healthy young men (weight, $75.2 \pm 5.5 \mathrm{~kg}$; height, $1.8 \pm 0.1 \mathrm{~m}$; age, $22.5 \pm 1.6$ years) were divided into two groups: high-trained $(n=8)$ and low-trained $(n=9)$. All participants performed: (a) one-repetition maximum (1RM) testing protocol on the leg press, (b) a unilateral training protocol $(4 \times 10$ repetitions at $70 \%$ of $1 \mathrm{RM}$ for leg press and $4 \times 10$ repetitions at $50 \%$ of $1 \mathrm{RM}$ for knee extension). Pre- and posttraining thermal images were recorded. The main results showed that independent of the limb (exercised vs. nonexercised), differences between lowand high-trained were observed for all regions of interest (ROI) except for the anterior knee: posttraining, 30-min and 60-min posttraining in nonexercised limb. The increase of contralateral Tsk was more than $50 \%$ on the ROls corresponding to the exercises muscles 30 -min posttraining in low-trained but was not so high in high-trained $(P<0.05)$. Low-trained subjects incremented more the Tsk than high-trained in both legs after exercise. In conclusion, we observed an acute contralateral Tsk effect to unilateral training on the Tsk of the nonexercised limb, reliant on the training level of the subject.

Keywords: Thermal imaging, Cross education, Neural training, Resistance training, Rehabilitation

\section{INTRODUCTION}

Unilateral strength motor activity has been used for rehabilitation purposes (Dragert and Zehr, 2011; Lee and Carroll, 2007). It has been demonstrated that contralateral strength training using training loads about $50 \%$ of the maximal voluntary strength, improves by $8 \%$ the initial strength values on the untrained limb and the increment on untrained limb correspond to the $25 \%$ $50 \%$ of the strength increment on the trained side, especially, on the homologous contralateral exercised areas (Carroll et al., 2006). Other studies have shown cross-education effects between $18 \%$ $77 \%$ of increments on strength values on the contralateral side with training loads higher than 85\% (Adamson et al., 2008; Farthing et al., 2007).
Unilateral strength training may also affect the contralateral muscles, because the neural signal is unfolding, stimulating commissural interneurons on the spinal cord, which act on the activation of contralateral motoneurons. Also, the neuromuscular system could provide adaptation to the untrained side improving neural drive to the agonist (Carroll et al., 2006; Lee and Carroll, 2007). A cortex contribution to produce that contralateral effect was presented by Lee et al. (2009). Studies did not show an increase in measures of cross-sectional area of the untrained muscles after unilateral resistance training, or even in the muscle enzymes and muscle fiber types (Beyer et al., 2016). So, muscular mechanism does not seem to be decisive on the registered strength improvement of the contralateral limb (Lee and Carroll, 2007). It is quite evident that peripheral adaptations unlikely appear after contralat-
${ }^{*}$ Corresponding author: Ciro José Brito (iD https://orcid.org/0000-0002-9678-1977 Departament of Physical Education, Federal University of Juiz de Fora (Campus Governador Valadares, Science Life Institute, José Lourenço Kelmer st., S/N Martelos, Juiz de Fora - MG 36036-330, Brazil

Tel: +55-33-3301-1000 (ext. 1555), E-mail: cirojbrito@gmail.com

Received: July 13, 2017 / Accepted: October 12, 2017 
eral training, due to insufficient stimulus for producing adaptations in the untrained limb. Neural mechanisms are the main responsible for contralateral strength gains after unilateral strength training (Carroll et al., 2006; Fimland et al., 2009). A recent study of Rattey et al. (2006) examined the effects of unilateral exercise and the contralateral fatigue in the nonexercised limb. Results obtained were an $8.7 \%$ decrement on the activation of the nonexercised limb. Probably, fatigue in the exercised limb was related to peripheral fatigue mechanisms. Meanwhile, central mechanisms were the factor that greater fatigued the nonexercised limb.

A significant increase during quadriceps muscle activation in a closed chain exercise to maximal fatigue was demonstrated by an increase in the electromyography (EMG) signal. Motor unit activation, and consequential fatigue, is specific to the performed activity of the trained muscle (Pincivero et al., 2006). Cross education can occur in both upper and lower limb muscles, as well as, with several training methods (Lee et al., 2014; Lee and Carroll, 2007; Sariyildiz et al., 2011). The strength gain is confined to the homologous muscle of the opposite untrained limb (Lee and Carroll, 2007; Sariyildiz et al., 2011; Zult et al., 2014), but the fact that the nonhomologous muscle is unaffected by training is important because contralateral effects have major joint specificity and would be greater when larger muscle groups are involved (Magnus et al., 2010) independently of sex or age (Ehsani et al., 2014).

Infrared thermography (IRT), as a noninvasive method, can result useful to control and recording the irradiated energy released from the body through the skin after strength training (Burnham et al., 2006), identify changes in body surface temperature and report the metabolism of active muscles (Chudecka and Lubkowska, 2012). It is widely known that there is a correlation between muscle activation and an increase in the skin temperature of the area adjacent to the muscles involved in the motor action, what is a result of increased metabolism of working muscles (Adamson et al., 2008). The muscles temperature at rest amounts about $36^{\circ} \mathrm{C}$, and rises from the beginning to the end of exercise, to $38^{\circ} \mathrm{C}$ (Adamczyk et al., 2014). The viscoelastic properties of the muscle use the energy stored during deformation for returning to its original shape; however, part of the accumulated energy dissipates as heat, and it relates with muscle activation and contraction (Van Loocke et al., 2008). It has been widely used with rehabilitation purposes, in assessment and reassessment after treatment (Cojocaru et al., 2015; Dimitrijevic et al., 2016; Magalhães et al., 2015).

Thermal asymmetries were correlated with pain intensity in patients with unilateral lumbosacral radiculopathy (Dimitrijevic et al., 2016), automatic detection of diabetic foot complications
(Liu et al., 2015) and breast cancer patients detection (de Jesus Guirro et al., 2017). In manual therapy, IRT has also been used to evaluate myofascial trigger points in soft tissues (Dibai-Filho and Guirro, 2015), neuro-musculoskeletal disorders and their dynamics (Cojocaru et al., 2015) and the noncontact, thermal evolution of soft tissues after compression treatment (Magalhães et al., 2015). In view of these data, it seems interesting to relate the influence of the unilateral strength training to the thermal response of both exercised and nonexercised limbs to understand better the physiological foundations of the cross-effect subsequent to this kind of training. We hypothesized that the contralateral training produces an acute thermal cross-effect in nonexercised limbs. In addition, the cross-effect depends on the considered ROI and the level of activity of the subject.

\section{MATERIALS AND METHODS}

\section{Approach to the problem}

We investigated with IRT acute contralateral Tsk on lower limb recording thermal images of the anterior lower limbs before, during and after unilateral strength training. On the first day of study, participants were engaged in one-repetition maximum (1RM) protocol to calculate the loads of the training day. The next day, after an appropriate acclimatization protocol of $15 \mathrm{~min}$ (Fernández-Cuevas et al., 2015), the first thermal image was recorded. Then, the participants performed the warm-up and the second thermal image was collected. Afterwards, they perform the training protocol and thermal images were registered immediately after training, $30 \mathrm{~min}$ and $60 \mathrm{~min}$ after training.

\section{Subjects}

The sample consisted of 17 healthy males, weight: $75.2 \pm 5.5 \mathrm{~kg}$ (Orbegozo weight scale, model PB2240, Zumarraga, Spain); height, $1.8 \pm 0.1 \mathrm{~m}$; age, $22.5 \pm 1.6$ years. According to levels of strength criteria they were divided into two groups: "high-trained" (1RM in leg press with one leg higher than the body weight: relative strength $>1)(\mathrm{n}=8$; age, $22.3 \pm 1.9$ years; weight, $76.1 \pm 4.3$ $\mathrm{kg}$; height, $1.8 \pm 0.1 \mathrm{~m}$ ) and "low-trained" (1RM in leg press with one leg lower than the body weight: relative strength $<1)(\mathrm{n}=9$; age, $22.7 \pm 1.1$ years; weight, $74.4 \pm 6.0 \mathrm{~kg}$; height, $1.78 \pm 0.03 \mathrm{~m}$ ). All the participants signed an informed consent, and this study was approved by the ethical committee of the university in which it was conducted, as a part of the research project "THERMOSPEC" in accordance with the Code of Ethics of the World Medical Association (Declaration of Helsinki). 

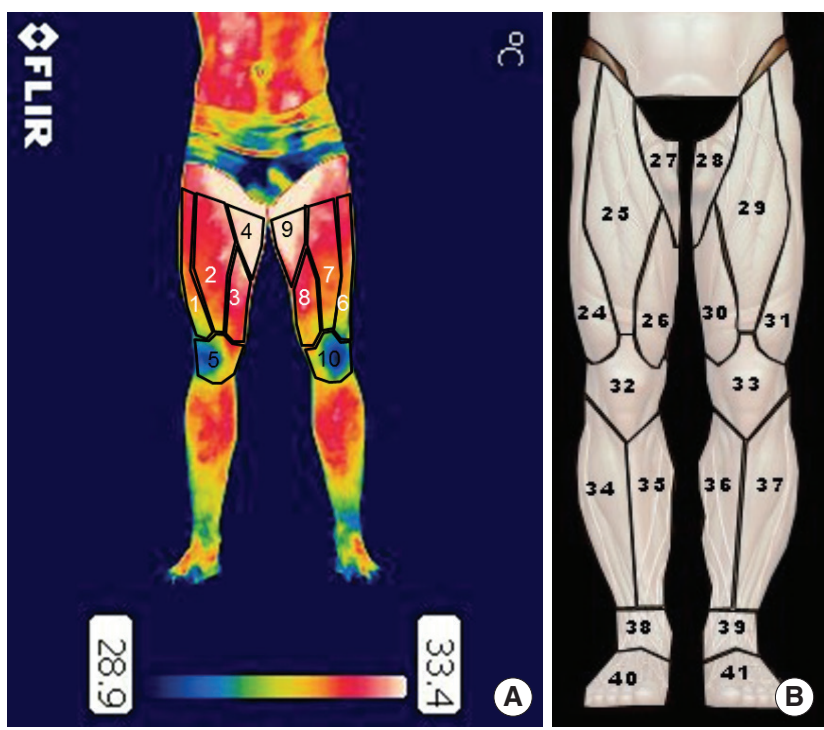

Fig. 1. Considered regions of interest (A) from the software Thermotracker areas (B). 1 \& 6, external thigh; 2 \& 7, central thigh; 3 \& 8, internal thigh; 4 \& 9, adductor; $5 \& 10$, knee (all of them will be named as exercised and nonexercised side).

\section{Procedures}

Previous to the thermography data collection, all the participants were instructed to avoid behaviors that may alter skin temperature (shower, tobacco, alcohol, coffee, etc.) in the night and prior hours before the protocol (Fernández-Cuevas et al., 2015). The thermal images were taken in an acclimated room (temperature, $21.0^{\circ} \mathrm{C} \pm 0.8^{\circ} \mathrm{C}$; humidity, $40.3 \% \pm 1.2 \%$; weather station BAR988HG, Oregon Scientific, Tualatin, OR, USA). For this was used an infrared camera (FLIR T335, FLIR Systems, Wilsonville, OR, USA), according the protocol described by Fernández-Cuevas et al. (2014). The Tsk data were analyzed by a thermographic software analyzer (Thermotracker, PemaGroup, Madrid, Spain). We considered the average values of 10 of the ROIs obtained by the Thermotracker on the thigh muscles and knees areas (Fig. 1).

For the 1RM test and the strength training two machines were used: a leg press (Free Weight Series, Panatta, Apiro, Macerata, Italy) and the knee extension (X Pression Series, Panatta, Apiro, Macerata, Italy). Before the 1RM test, the subjects performed a 5-min warm-up including cycling at $100 \mathrm{~W}$ some dynamic stretching for lower body and completed 10 repetitions of back squat only with an Olympic bar. Afterwards, in order to prevent fatigue (Taylor et al., 2012), they had five attempts to achieve the $1 \mathrm{RM}$ with each leg in the two considered exercises (leg press and knee extension) with a random order for leg and exercise.

The training sessions included a warm-up of 5-min cycling at
$100 \mathrm{~W}$ followed by some dynamic lower body stretching and finished with ten repetitions of back squat only with an Olympic bar. The unilateral training exercises and procedures were based on Fernández-Cuevas et al. (2014); choosing leg press and knee extension as exercises. The participants performed 4 sets of 10 repetitions at $70 \%$ of $1 \mathrm{RM}$ for leg press and $50 \%$ of $1 \mathrm{RM}$ for knee extension with a 2:2 rhythm (2-sec eccentric and 2-sec concentric). The resting period was $90 \mathrm{sec}$ between sets and 3 min after each exercise. Each exercise was performed only with the strong leg, determined by the leg with higher 1RM in the leg press machine, according to Velotta et al. (2011) and Farthing (2009).

\section{Statistical analysis}

Exploratory data analysis was performed for identification and correction of extreme values. Normality and homoscedasticity were tested using the Kolmogorov-Smirnov test and the Bartlett's criteria, respectively. The analysis of variance (ANOVA) with three factors (training level $\times$ strength $\operatorname{leg} \times$ measurement time) was used to establish the difference between means. For validation of repeated measurements, the Mauchly sphericity test was used and, whenever necessary, Greenhouse-Geisser correction was applied. If a significant difference was observed in the ANOVA, the post hoc Bonferroni test was used to identify the significant differences among categories. When main effect and interaction were found, only the interaction effect was reported. The magnitude of treatment effects was calculated using eta squared effect size. In all analyses, significance level of $P<0.05$ was adopted.

\section{RESULTS}

The statistical analysis indicated an interaction effect between the level of training and ROI $\left(F=24.373, P<0.001, \eta^{2}=0.89\right)$ and between the level of training and moment of measurement $\left(F=51.376, P<0.001, \eta^{2}=0.945\right)$; when applied to sphericity correction there was a significant interaction effect between the level of training, ROI and time measurement $(F=15.855, P<$ $0.001, \eta^{2}=0.514$ ). Table 1 shows the descriptive data (mean \pm standard deviation) for all the considered ROI for both the exercised (strong) and the nonexercised (weak) legs in the low- and high-trained group. They indicated significant differences between exercised and nonexercised ROIs and between data collection moments.

Table 2 shows the statistical differences obtained between training level by trained leg, ROI, and time of measurement. For exercised leg, in general, the results indicated significant differences on 
Table 1. Summary of temperature for anterior view for low- and high-trained group

\begin{tabular}{|c|c|c|c|c|c|c|c|}
\hline Group & $\mathrm{ROI}$ & Limbs & Pre-exercise & After warm-up & Postexercise & $30 \mathrm{Min}$ & 60 Min \\
\hline \multirow[t]{10}{*}{ Low-trained } & \multirow[t]{2}{*}{ Adductor } & Exercised & $30.1 \pm 1.3$ & $29.1 \pm 1.6^{a)}$ & $29.8 \pm 1.5$ & $30.4 \pm 1.1$ & $30.5 \pm 1.1$ \\
\hline & & Nonexercised & $30.2 \pm 1.2$ & $29.1 \pm 1.6^{\text {b) }}$ & $29.7 \pm 1.5^{\mathrm{c})}$ & $30.4 \pm 1.1$ & $30.4 \pm 1.1$ \\
\hline & \multirow[t]{2}{*}{ Central thigh } & Exercised & $29.5 \pm 1.1$ & $28.8 \pm 1.3^{\mathrm{d})}$ & $30.3 \pm 1.5$ & $31.1 \pm 0.9$ & $30.8 \pm 0.9$ \\
\hline & & Nonexercised & $29.7 \pm 1.0$ & $28.8 \pm 1.3^{\mathrm{e})}$ & $29.6 \pm 1.4$ & $30.4 \pm 1.0$ & $30.3 \pm 0.9$ \\
\hline & \multirow[t]{2}{*}{ External thigh } & Exercised & $29.2 \pm 0.8^{f \dagger}$ & $29.0 \pm 0.9^{9)}$ & $30.2 \pm 1.2$ & $30.7 \pm 0.7$ & $30.3 \pm 0.9$ \\
\hline & & Nonexercised & $29.3 \pm 0.9$ & $28.8 \pm 1.1^{h)}$ & $29.2 \pm 1.2$ & $29.5 \pm 0.9^{i)}$ & $29.4 \pm 0.7$ \\
\hline & \multirow[t]{2}{*}{ Internal thigh } & Exercised & $28.9 \pm 1.1$ & $28.8 \pm 1.3^{\mathrm{j})}$ & $30.3 \pm 1.3$ & $30.1 \pm 1.0$ & $29.4 \pm 0.8$ \\
\hline & & Nonexercised & $29.1 \pm 1.0$ & $28.8 \pm 1.4$ & $29.0 \pm 1.1$ & $29.4 \pm 1.1$ & $29.2 \pm 0.9$ \\
\hline & \multirow[t]{2}{*}{ Knee } & Exercised & $28.1 \pm 1.4$ & $27.7 \pm 1.2$ & $28.3 \pm 1.2$ & $27.8 \pm 1.2$ & $27.4 \pm 0.9$ \\
\hline & & Nonexercised & $28.2 \pm 1.3$ & $27.8 \pm 1.2$ & $27.5 \pm 0.9$ & $27.3 \pm 1.0$ & $27.0 \pm 0.8$ \\
\hline \multirow[t]{10}{*}{ High-trained } & \multirow[t]{2}{*}{ Adductor } & Exercised & $31.8 \pm 1.0$ & $30.9 \pm 0.8$ & $31.4 \pm 0.8$ & $32.1 \pm 0.5$ & $32.1 \pm 0.7$ \\
\hline & & Nonexercised & $31.9 \pm 0.8$ & $30.9 \pm 0.7^{k)}$ & $31.3 \pm 0.7^{\prime \prime}$ & $32.1 \pm 0.5$ & $32.1 \pm 0.7$ \\
\hline & \multirow[t]{2}{*}{ Central thigh } & Exercised & $31.4 \pm 0.9$ & $30.7 \pm 0.7^{\mathrm{m})}$ & $32.0 \pm 0.9$ & $32.6 \pm 0.4$ & $32.1 \pm 0.5$ \\
\hline & & Nonexercised & $31.5 \pm 0.7$ & $30.7 \pm 0.8^{n)}$ & $30.7 \pm 1.0^{\circ)}$ & $31.7 \pm 0.4$ & $31.6 \pm 0.7$ \\
\hline & \multirow[t]{2}{*}{ External thigh } & Exercised & $30.9 \pm 1.0$ & $30.7 \pm 0.7$ & $31.6 \pm 1.0$ & $31.9 \pm 0.6$ & $31.3 \pm 0.7$ \\
\hline & & Nonexercised & $30.7 \pm 0.7$ & $30.4 \pm 0.7$ & $29.9 \pm 1.0$ & $30.7 \pm 0.5$ & $30.5 \pm 0.6$ \\
\hline & \multirow[t]{2}{*}{ Internal thigh } & Exercised & $30.8 \pm 0.7$ & $30.6 \pm 0.7$ & $31.9 \pm 1.0$ & $31.8 \pm 0.7$ & $31.1 \pm 0.7$ \\
\hline & & Nonexercised & $30.8 \pm 0.5$ & $30.7 \pm 0.7$ & $30.1 \pm 1.1$ & $30.9 \pm 0.6$ & $30.6 \pm 0.7$ \\
\hline & \multirow[t]{2}{*}{ Knee } & Exercised & $29.3 \pm 0.8$ & $28.7 \pm 0.8$ & $28.7 \pm 1.3$ & $29.0 \pm 0.9$ & $28.4 \pm 1.0$ \\
\hline & & Nonexercised & $29.4 \pm 0.8$ & $28.7 \pm 0.9$ & $27.7 \pm 1.3$ & $28.2 \pm 0.8$ & $27.8 \pm 1.0$ \\
\hline
\end{tabular}

Values are presented as mean \pm standard deviation.

$\mathrm{ROI}$, region of interest; Ant, anterior; Ext, external; Int, internal.

a) $P=0.012$ after warm-up vs. $30 \mathrm{~min}$ (difference [dif.], $-1.2^{\circ} \mathrm{C} \pm 0.3^{\circ} \mathrm{C} ; 95 \%$ confidence interval [Cl], -2.13 to -0.28 ). ${ }^{\text {b) }} P=0.04$ after warm-up vs. 30 min and 60 min (dif., $-1.3^{\circ} \mathrm{C} \pm 0.3^{\circ} \mathrm{C}$; $95 \% \mathrm{Cl},-2.5$ to 0.56 ). ${ }^{\text {c) }} P=0.048$ postexercise vs. $60 \mathrm{~min}$ (dif., $-0.8^{\circ} \mathrm{C} \pm 0.2^{\circ} \mathrm{C} ; 95 \% \mathrm{Cl},-1.61$ to 0.06 ). ${ }^{\text {d) }} P=0.012$ after warm-up vs. postexercise; 30 and 60 min (dif., $-1.3^{\circ} \mathrm{C} \pm 0.2^{\circ} \mathrm{C}$; $95 \% \mathrm{Cl},-2.12$ to 0.5 ). ${ }^{\text {e) }} \mathrm{P}=0.004$ after warm-up vs. postexercise; 30 and $60 \mathrm{~min}$ (dif., $-1.4^{\circ} \mathrm{C} \pm 0.2^{\circ} \mathrm{C} ; 95 \% \mathrm{Cl},-2.21$ to 0.5 ); ${ }^{\text {f) }} P=0.045$ pre-exercise vs. 30 min (dif., $-1.5^{\circ} \mathrm{C} \pm 0.3^{\circ} \mathrm{C}$; $95 \% \mathrm{Cl},-2.89$ to 0.03 ). ${ }^{\text {g) }} \mathrm{P}=0.014$ after warm-up vs. postexercise; 30 and $60 \mathrm{~min}$ (dif., $-1.5^{\circ} \mathrm{C} \pm 0.3^{\circ} \mathrm{C} ; 95 \% \mathrm{Cl},-2.61$ to 0.31 ). h) $P=0.012$ after warm-up vs. postexercise (dif., $-1.2^{\circ} \mathrm{C} \pm 0.2^{\circ} \mathrm{C} ; 95 \% \mathrm{Cl},-2.19$ to 0.29 ). i) $P=0.03230$ min vs. 60 min (dif., $-0.7^{\circ} \mathrm{C} \pm 0.2^{\circ} \mathrm{C} ; 95 \% \mathrm{Cl},-1.36$ to 0.06 ). ${ }^{j} P=0.035$ after warm-up vs. postexercise and 30 min (dif., $-1.3^{\circ} \mathrm{C} \pm 0.3^{\circ} \mathrm{C} ; 95 \% \mathrm{Cl},-2.49$ to 0.09). $\left.{ }^{k}\right) P=0.023$ after warm-up vs. 30 and 60 min (dif., $-1.2^{\circ} \mathrm{C} \pm 0.3^{\circ} \mathrm{C} ; 95 \%$ Cl, -2.22 to 0.16 ). ${ }^{\prime \prime} P=0.015$ postexercise vs. 60 min (dif., $-0.9^{\circ} \mathrm{C} \pm 0.2^{\circ} \mathrm{C}$; $95 \% \mathrm{Cl},-1.58$ to 0.18 ). ${ }^{\mathrm{m})} \mathrm{P}=0.031$ after warm-up vs. $30 \mathrm{~min}$ (dif., $-1.0^{\circ} \mathrm{C} \pm 0.2^{\circ} \mathrm{C}$; $95 \% \mathrm{Cl},-1.96$ to 0.09 ). ${ }^{\text {n) }} P=0.017$ after warm-up vs. 30 and 60 min (dif., $-1.5^{\circ} \mathrm{C} \pm 0.3^{\circ} \mathrm{C} ; 95 \%$, -2.71 to 0.28 ). ${ }^{\circ} \mathrm{P}=0.031$ postexercise vs. $60 \mathrm{~min}$ (dif., $-1.0^{\circ} \mathrm{C} \pm 0.3^{\circ} \mathrm{C} ; 95 \% \mathrm{Cl},-1.85$ to 0.09 ).

Tsk except for the external thigh (60 min) and knee (after warmup, for $30 \mathrm{~min}$, for $60 \mathrm{~min}$ ). For nonexercised leg, significant differences were observed at all measured moments for the adductor and external thigh. in central and internal thigh, we observed differences in all moments of measurement except postexercise.

Table 3 summarizes the evolution of Tsk considering the after warming-up values as the baseline. A general tendency has been estimated by obtaining the average of the considered ROIs. In general, the initial Tsk's was reduced after warming-up and recovered immediately after exercise, increasing the values $30 \mathrm{~min}$ after exercise and remaining higher $60 \mathrm{~min}$ after exercise. This tendency was stronger in low-trained group than in high-trained group.

\section{DISCUSSION}

Unilateral training can be recommended in different situations of physical training, such as in rehabilitation (Dragert and Zehr,
2011). This study verified the influence of the unilateral strength training on the skin thermal response for both exercised and nonexercised limbs in low- and high-trained subjects. The main results indicated differences immediately after exercise between both exercised and nonexercised limb and low- and high-trained participants in several moments of measurement for all ROI except for the anterior knee. At 30-min postexercise in nonexercised limb differences also were observed in all ROIs except for the anterior knee. The comparison between groups probed that lowtrained subjects incremented more the Tsk after exercise in both legs than high-trained. Unilateral training may also influence the contralateral muscles, because the neural signal is unfolding, stimulating commissural interneurons on the spinal cord, which act on the activation of contralateral motoneurons. Also, the neuromuscular system could provide adaptation to the untrained side improving neural drive to the agonist (Carroll et al., 2006; Lee and Carroll, 2007). 
Table 2. Summary of temperature $\left({ }^{\circ} \mathrm{C}\right)$ differences between high- and low-trained group for exercised and nonexercised leg

\begin{tabular}{|c|c|c|c|c|c|c|c|}
\hline Limb & ROl & Value & Pre-exercise & After warm-up & Postexercise & $30 \mathrm{Min}$ & $60 \mathrm{Min}$ \\
\hline \multirow[t]{15}{*}{ Exercised } & Adductor & Difference & $-1.6 \pm 1.9^{*}$ & $-1.7 \pm 1.7^{*}$ & $-1.7 \pm 1.2^{*}$ & $-1.9 \pm 1.5^{*}$ & $-1.6 \pm 1.4^{*}$ \\
\hline & & $95 \% \mathrm{Cl}$ & -2.69 to -0.79 & -3.16 to -0.71 & -3.19 to -0.2 & -2.77 to -0.9 & -2.4 to -0.81 \\
\hline & & $P$-value & 0.003 & 0.007 & 0.032 & 0.002 & 0.002 \\
\hline & Central thigh & Difference & $-1.9 \pm 1.7^{*}$ & $-1.8 \pm 1.3^{*}$ & $-1.9 \pm 1.3^{*}$ & $-1.6 \pm 0.7^{*}$ & $-1.3 \pm 1.3^{*}$ \\
\hline & & $95 \% \mathrm{Cl}$ & -2.78 to -1.13 & -3.1 to -0.7 & -3.31 to -0.38 & -2.38 to -0.8 & -2.3 to -0.25 \\
\hline & & $P$-value & 0.001 & 0.007 & 0.021 & 0.003 & 0.022 \\
\hline & External thigh & Difference & $-1.6 \pm 1.6^{*}$ & $-1.6 \pm 1.1^{*}$ & $-1.5 \pm 1.1^{*}$ & $-1.3 \pm 1.1^{*}$ & $-1,0 \pm 1.1$ \\
\hline & & $95 \% \mathrm{Cl}$ & -2.48 to -0.88 & -2.58 to -0.56 & -2.79 to -0.21 & -2.2 to -0.38 & -0.23 to 2.2 \\
\hline & & $P$-value & 0.002 & 0.008 & 0.028 & 0.012 & 0.097 \\
\hline & Internal thigh & Difference & $-1.8 \pm 1.4^{*}$ & $-1.7 \pm 1.5^{*}$ & $-1.8 \pm 1.4^{*}$ & $-1.8 \pm 1.4^{*}$ & $-1.8 \pm 1.5^{*}$ \\
\hline & & $95 \% \mathrm{Cl}$ & -3.14 to -1.13 & -3.52 to -0.46 & -3.25 to -0.25 & -3.0 to -0.63 & -2.89 to -0.6 \\
\hline & & $P$-value & 0.002 & 0.018 & 0.028 & 0.009 & 0.008 \\
\hline & Knee & Difference & $-1.1 \pm 1.9^{*}$ & $-1,2 \pm 1.0$ & $-0,7 \pm 0.9$ & $-1,4 \pm 1.1$ & $-1,2 \pm 1.1$ \\
\hline & & $95 \% \mathrm{Cl}$ & -2.73 to -0.21 & -0.13 to 2.59 & -0.68 to 2.03 & -0.28 to 2.8 & -0.29 to 2.6 \\
\hline & & $P$-value & 0.028 & 0.07 & 0.278 & 0.054 & 0.101 \\
\hline \multirow[t]{15}{*}{ Nonexercised } & Adductor & Difference & $-1.7 \pm 1.7^{*}$ & $-1.7 \pm 1.7^{*}$ & $-1.6 \pm 1.6^{*}$ & $-1.6 \pm 0.8^{*}$ & $-1.7 \pm 1.2^{*}$ \\
\hline & & $95 \% \mathrm{Cl}$ & -2.78 to -0.88 & -3.12 to -0.66 & -3.34 to -0.28 & -2.96 to -0.8 & -2.9 to -0.53 \\
\hline & & $P$-value & 0.003 & 0.008 & 0.027 & 0.005 & 0.011 \\
\hline & Central thigh & Difference & $-1.9 \pm 1.5^{*}$ & $-1.8 \pm 1.3^{*}$ & $-1,4 \pm 1.0$ & $-1.2 \pm 0.7^{*}$ & $-1.2 \pm 0.9^{*}$ \\
\hline & & $95 \% \mathrm{Cl}$ & -2.78 to -1.11 & -3.27 to -0.59 & -0.69 to 2.81 & -2.54 to 0.37 & -2.48 to -0.1 \\
\hline & & $P$-value & 0.001 & 0.012 & 0.059 & 0.016 & 0.041 \\
\hline & External thigh & Difference & $-1.4 \pm 1.4^{*}$ & $-1.6 \pm 1.2^{*}$ & $-1.0 \pm 0.6^{*}$ & $-1.1 \pm 0.9^{*}$ & $-1.1 \pm 0.8^{*}$ \\
\hline & & $95 \% \mathrm{Cl}$ & -2.45 to -0.69 & -2.79 to -0.61 & -0.29 to 2.2 & $-2.34-0.22$ & -2.21 to -0.2 \\
\hline & & $P$-value & 0.004 & 0.008 & 0.113 & 0.024 & 0.028 \\
\hline & Internal thigh & Difference & $-1.6 \pm 1.3^{*}$ & $-1.8 \pm 1.3^{*}$ & $-1,3 \pm 1.0$ & $-1.4 \pm 0.7^{*}$ & $-1.3 \pm 0.7^{*}$ \\
\hline & & $95 \% \mathrm{Cl}$ & -2.73 to -1.08 & -3.51 to -0.32 & -0.14 to 2.77 & $0.29-2.89$ & 0.09 to 2.63 \\
\hline & & $P$-value & 0.001 & 0.025 & 0.07 & 0.023 & 0.039 \\
\hline & Knee & Difference & $-1.4 \pm 0.7$ & $-1.1 \pm 0.5$ & $-0.3 \pm 0.4$ & $-1.0 \pm 1.3$ & $-0.9 \pm 0.6$ \\
\hline & & $95 \% \mathrm{Cl}$ & -0.13 to 2.83 & -0.34 to 2.5 & 1.16 to 1.8 & -0.53 to 2.23 & -0.45 to 2.2 \\
\hline & & $P$-value & 0.052 & 0.106 & 0.627 & 0.059 & 0.165 \\
\hline
\end{tabular}

Values are presented as mean \pm standard deviation

$\mathrm{ROI}$, region of interest; $\mathrm{Cl}$, confidence interval.

${ }^{*} P<0.05$, significant differences between low- and high-trained.

\section{Tsk response to the strength exercise}

The Tsk behavior has been considered in previous studies, in which agonist muscles obtained maximal Tsk values not immediately after training but during the recovery process (de Andrade Fernandes et al., 2016; Fernández-Cuevas et al., 2014). The increment of Tsk could be due to an increased activation of involved muscles that releases more energy after being exercised (Adamczyk et al., 2014). It is widely known that the increment of temperature during exercise causes disturbances in thermoregulation system of the human body (Formenti et al., 2013) to allow maintaining the temperature homeostasis altered by exercises of different intensity and duration (de Andrade Fernandes et al., 2016; Ferreira et al., 2008). The most relevant thermoregulation system med- itated by nervous system tries to become the Tsk symmetrical (Niu et al., 2001). In that way, the body attempts to control the temperature exchange between human body and environment.

In our study, the ROIs corresponding to the muscles involved in exercise had a Tsk increment immediately after exercise. This increase was more specific to the muscles exercised in strength training. This behavior agrees with the results of Fernández-Cuevas et al. (2014) that obtained Tsk increments on agonist muscles after a strength training of upper and lower limbs. However, the effects could be slightly different in our study because the blood flow had to be redistributed only in the lower area. In addition, the expected cross-effect response on the Tsk took place on the homologous agonist's muscles of the nonexercised leg. A similar 
Table 3. Variation of Tsk values $(\Delta)$ in ${ }^{\circ} \mathrm{C}$ with after warming-up values as baseline

\begin{tabular}{|c|c|c|c|c|c|c|c|}
\hline Group & ROI & Limb & $\Delta$ Pre-exercise & $\begin{array}{l}\text { After warm-up } \\
\text { (baseline) }\end{array}$ & $\Delta$ Postexercise & $\Delta 30 \mathrm{Min}$ & $\Delta 60 \mathrm{Min}$ \\
\hline \multirow[t]{12}{*}{ Low-trained } & \multirow[t]{2}{*}{ Adductor } & Exercised & 1.1 & 29.1 & 0.7 & 1.3 & 1.4 \\
\hline & & Nonexercised & 1.1 & 29.1 & 0.6 & 1.3 & 1.3 \\
\hline & \multirow[t]{2}{*}{ Central thigh } & Exercised & 0.7 & 28.8 & 1.5 & 2.3 & 2.0 \\
\hline & & Nonexercised & 0.9 & 28.8 & 0.8 & 1.6 & 1.5 \\
\hline & \multirow[t]{2}{*}{ External thigh } & Exercised & 0.2 & 29.0 & 1.2 & 1.7 & 1.3 \\
\hline & & Nonexercised & 0.5 & 28.8 & 0.4 & 0.7 & 0.6 \\
\hline & \multirow[t]{2}{*}{ Internal thigh } & Exercised & 0.1 & 28.8 & 1.5 & 1.3 & 0.6 \\
\hline & & Nonexercised & 0.3 & 28.8 & 0.2 & 0.6 & 0.4 \\
\hline & \multirow[t]{2}{*}{ Knee } & Exercised & 0.4 & 27.7 & 0.6 & 0.1 & -0.3 \\
\hline & & Nonexercised & 0.4 & 27.8 & -0.3 & -0.5 & -0.8 \\
\hline & \multirow[t]{2}{*}{ General (average) } & Exercised & 0.48 & 28.7 & 1.1 & 1.34 & 1.0 \\
\hline & & Nonexercised & 0.64 & 28.7 & 0.34 & 0.74 & 0.6 \\
\hline \multirow[t]{12}{*}{ High-trained } & \multirow[t]{2}{*}{ Adductor } & Exercised & 0.9 & 30.9 & 0.5 & 1.2 & 1.2 \\
\hline & & Nonexercised & 1.1 & 30.9 & 0.4 & 1.2 & 1.2 \\
\hline & \multirow[t]{2}{*}{ Central thigh } & Exercised & 0.7 & 30.7 & 1.3 & 1.9 & 1.4 \\
\hline & & Nonexercised & 0.8 & 30.7 & 0.0 & 1.0 & 0.9 \\
\hline & \multirow[t]{2}{*}{ External thigh } & Exercised & 0.2 & 30.7 & 0.9 & 1.2 & 0.6 \\
\hline & & Nonexercised & 0.3 & 30.4 & -0.5 & 0.3 & 0.1 \\
\hline & \multirow[t]{2}{*}{ Internal thigh } & Exercised & 0.2 & 30.6 & 1.3 & 1.2 & 0.5 \\
\hline & & Nonexercised & 0.1 & 30.7 & -0.6 & 0.2 & -0.1 \\
\hline & \multirow[t]{2}{*}{ Knee } & Exercised & 0.6 & 28.7 & 0.0 & 0.3 & -0.3 \\
\hline & & Nonexercised & 0.7 & 28.7 & -1.0 & -0.5 & -0.9 \\
\hline & \multirow[t]{2}{*}{ General (average) } & Exercised & 0.52 & 30.3 & 0.8 & 1.16 & 0.68 \\
\hline & & Nonexercised & 0.58 & 30.3 & -0.34 & 0.44 & 0.24 \\
\hline
\end{tabular}

Tsk, skin temperature.

physiological response to unilateral training has been obtained previously with unilateral training measured with EMG (Beyer et al., 2016; Pincivero et al., 2006) and, being measured with other methods, the contralateral effect is only produced in the homologous muscles that were doing the activity (Chiesa et al., 2016).

Inner muscle temperature increment after strength training depends on time under tension and speed of contraction of the muscles involved in the activity (Marins et al., 2011). In the same way, Tsk variation registered on the nonexercised leg could also be reflecting the different level of activation in those muscles. To sum up, the energy (heat) produced by the muscle during contraction it is unable to drive out, so it is stored in muscle tissue (Kenny et al., 2008). The restoring of the normal blood flow to the skin after finishing the exercise with blood proceeding from activated muscles increases also the heat in the skin area corresponding to those muscles (Merla et al., 2010).

The causes for the Tsk increment in nonexercised leg are not clear, because it has not been measured Tsk simultaneously with other neural parameters (EMG) or biochemical parameters (levels of creatine-phosphokinase). According to the recent review of contralateral training of Lee et al. (2009), we think that this increment may be linked to the neural mechanisms related to cross effect. In the study of Rattey et al. (2006) the acute fatigue appeared on both exercised leg and on homologous muscles of nonexercised leg seems also to be related to neural factors. Although, it cannot dismiss a muscular factor as a transformation of satellite cells form inactive to active, hypertrophy or change on fiber type interfere in cross effect.

\section{Tsk response to the strength exercise along the time}

In the initial rest state, the Tsk should be equal on both sides for humans (Niu et al., 2001). Our data show how nonexercised and exercised legs had symmetrical distributions of Tsk both in high and low-trained subject, on all the considered ROI of the lower limb at pre-exercise, assuming that participants started the training protocols in an optimal rest state. The general decrease of Tsk after warm-up goes in line with the research of Adamczyk et al. (2012). Their study shown that the decrease on quadriceps Tsk is directly related with the power performance measured with a 
countermovement jump. Other authors provided also information about a fall in the skin temperature in the initial period of exercise (de Andrade Fernandes et al., 2016; Fernández-Cuevas et al., 2014; Marins et al., 2011). The temperature drops immediately after exercise induces a higher relative increase in the subsequent moments of recovery, making more relevant the differences in the moments after training. Hence, in future research it could be important consider the temperature before and after the warm-up to verify the acute effect or behavior of Tsk to the exercise.

Immediately after training, in the exercised leg, the ROIs corresponding to the involved muscles exhibit an increment of temperature, normally significant. It could be inferred during the warm-up it is activated the physiological response of blood flow redistribution in order to provide nutrients to the active muscles facilitated by a vasoconstriction of the skin vessels. The energy generated by the active muscles is not enough to generate a Tsk increase at skin level. However, with a higher volume or intensity of work and a certain time after starting the muscle activity, the heat produced in muscle may reach the skin level being probably transferred by conduction (from hotter inner muscles to colder outer tissues) and mainly by the restauration of the normal blood flow to the skin with warmer blood from the active muscles; so that, the Tsk increases after exercise (Kenny et al., 2008). Further research should be done in order to understand better the dynamics of Tsk due to the different types of exercise.

On the other hand, the Tsk on the nonexercised leg of our subjects remained at the baseline levels immediately after exercise. These results agree with previous studies where, under normal conditions, the temperature tends to be constant (Formenti et al., 2016; Okazaki, 2016). However, $30 \mathrm{~min}$ after exercise, were recorded the maximum Tsk values along the study for both legs in the ROIs of the involved muscles. This is a remarkable fact because the nonexercised leg did not perform any activity. They have been not found studies about the contralateral effect on Tsk measured with any alternative method, although the cross-education effects are widely known and it has been demonstrated an increment of strength and an acute contralateral fatigue of nonexercised limb (Lee and Carroll, 2007; Rattey et al., 2006). Our data about the Tsk increase on nonexercised leg $30 \mathrm{~min}$ after training could be considered as directly related to the already probed contralateral effect. We will name it as "acute contralateral Tsk effect" (ACTsk), and it could be assumed as half of the increment generated on the exercised leg $30 \mathrm{~min}$ after strength training.

Finally, 60 min after training, the Tsk on the muscle areas involved in the performed exercise was maintained or slightly de- creased compared to $30 \mathrm{~min}$ after exercise and also on the homologous nonexercised muscle, which means that the ACTsk is maintained at least up to an hour after training. The excess postexercise oxygen consumption should be one of the variables responsible for the Tsk increment due to the increased metabolism after exercise (Laforgia et al., 2006). In contrast, the nonexercised muscle areas tend to recover the baseline temperature controlled by the thermoregulatory system.

\section{Differences between high- and low-trained subjects}

It is interesting to point out that baseline data (pre-exercise) are more than $1^{\circ} \mathrm{C}$ higher in high-trained group (Tables 1,3$)$. This is probably due to a higher muscle activation and blood flow in high-trained subjects. The higher Tsk values recorded on hightrained indicate that the level of training is a factor of influence to be considered during the interpretation of thermograms after exercise. The thermal behavior differs between high- and lowtrained subjects (Formenti et al., 2013). Previous studies have established these differences based on changes of the thermoregulation processes depending on the physical level of the subject (Adamczyk et al., 2016; Boguszewski et al., 2014). Low-trained subjects release the heat worse than high-trained during exercise and maintain the heat longer time during the recovery process (Formenti et al., 2013).

In our study, the low-trained participants showed a higher increment in absolute Tsk values than high-trained after exercise. A probable explanation is that high-trained athletes recruit more synergist muscles to perform the same action reducing the requirements to the agonist muscles. The increment on absolute Tsk could be due to the fact that high-trained delay the Tsk increment and they dissipate the heat better than low-trained (Formenti et al., 2013). In addition, the high-trained athletes performed with higher absolute workload and have more level of performance and better neural drive. These facts could make that high-trained involved more muscles in action than low-trained (Fimland et al., 2009).

This study reinforces the idea of use thermography as sport tool to quantify the training load, providing information about the exercise selection and the effect of training on the body. The acute Tsk crossed effect indicates a training adaptation to unilateral strength training and coaches could utilize the unilateral training as a useful method of strength training; however, they should consider some aspects, as the acute prefatigue generated on nonexercised limb, before performing exercise with the other limb. IRT could be used to assess and monitor the effects of unilateral train- 
ing during rehabilitation, to prevent loss of strength in the affected or immobilized limb. The differences between the low-trained and the high-trained must be also considered by coaches, since the same exercise involve different activation of the muscle to perform the activity, being highly trained who recruit more synergist muscle probably due to a better coordination or neural communication, and the fact that they mobilize higher absolute load.

To conclude, it can be said that after contralateral training Tsk has a significant increment both on ROIs corresponding to exercised muscles and on the contralateral nonexercised muscles. However, the joints have different behavior exhibiting a detriment on Tsk after training. The peak of Tsk in both exercised and nonexercised leg was produced around $30 \mathrm{~min}$ after training. On the nonexercised leg, this increase corresponds to half of exercised leg increment. So that, the Tsk response to contralateral training seems to be related to the cross-effect and set up ACTsk to monolateral strength training. The ACTsk is more accentuated in low-trained than in high-trained subjects. Using IRT as a measurement method, it has been demonstrated an acute Tsk crossed effect in the nonexercised limb as a response to the unilateral strength training.

\section{CONFLICT OF INTEREST}

No potential conflict of interest relevant to this article was reported.

\section{ACKNOWLEDGMENTS}

This study was funded by Technic University of Madrid (UPM).

\section{REFERENCES}

Adamczyk JG, Boguszewski D, Siewierski M. Physical effort ability in counter movement jump depending on the kind of warm-up and surface temperature of the quadriceps. Baltic J Health Phys Act 2012;4: 164-171.

Adamczyk JG, Mastej M, Boguszewski D, Białoszewski D. Usage of thermography as indirect non-invasive method of evaluation of physical efficiency. Pilot study. Pedag Psychol Med-Biol Probl Phys Train Sports 2014;3:90-95.

Adamczyk JG, Olszewska M, Boguszewski D, Białoszewski D, Reaburn P. Is it possible to create a thermal model of warm-up? Monitoring of the training process in athletic decathlon. Infrared Phys Technol 2016;76:555-559.

Adamson M, Macquaide N, Helgerud J, Hoff J, Kemi OJ. Unilateral arm strength training improves contralateral peak force and rate of force development. Eur J Appl Physiol 2008;103:553-559.

Beyer KS, Fukuda DH, Boone CH, Wells AJ, Townsend JR, Jajtner AR, Gonzalez AM, Fragala MS, Hoffman JR, Stout JR. Short-term unilateral resistance training results in cross education of strength without changes in muscle size, activation, or endocrine response. J Strength Cond Res 2016;30:1213-1223.

Boguszewski D, Adamczyk JG, Urbańska N, Mrozek N, Piejko K, Janicka $\mathrm{M}$, Białoszewski D. Using thermal imaging to assess the effect of classical massage on selected physiological parameters of upper limbs. Biomed Hum Kinetics 2014;6:146-150.

Burnham RS, McKinley RS, Vincent DD. Three types of skin-surface thermometers: a comparison of reliability, validity, and responsiveness. Am J Phys Med Rehabil 2006;85:553-558.

Carroll TJ, Herbert RD, Munn J, Lee M, Gandevia SC. Contralateral effects of unilateral strength training: evidence and possible mechanisms. J Appl Physiol (1985) 2006;101:1514-1522.

Chiesa ST, Trangmar SJ, González-Alonso J. Temperature and blood flow distribution in the human leg during passive heat stress. J Appl Physiol (1985) 2016;120:1047-1058.

Chudecka M, Lubkowska A. The use of thermal imaging to evaluate body temperature changes of athletes during training and a study on the impact of physiological and morphological factors on skin temperature. Hum Mov 2012;13:33-39.

Cojocaru MC, Cojocaru IM, Voiculescu VM, Cojan-Carlea NA, Dumitru VL, Berteanu M. Trigger points--ultrasound and thermal findings. J Med Life 2015;8:315-318.

de Andrade Fernandes A, dos Santos Amorim RR, Brito CJ, Sillero-Quintana M, Bouzas Marins JC. Regional skin temperature response to moderate aerobic exercise measured by infrared thermography. Asian J Sports Med 2016;7:e29243.

de Jesus Guirro RR, Oliveira Lima Leite Vaz MM, das Neves LMS, Dibai-Filho AV, Carrara HHA, de Oliveira Guirro EC. Accuracy and reliability of infrared thermography in assessment of the breasts of women affected by cancer. J Med Syst 2017;41:87.

Dibai-Filho AV, Guirro RR. Evaluation of myofascial trigger points using infrared thermography: a critical review of the literature. J Manipulative Physiol Ther 2015;38:86-92.

Dimitrijevic IM, Kocic MN, Lazovic MP, Mancic DD, Marinkovic OK, Zlatanovic DS. Correlation of thermal deficit with clinical parameters and functional status in patients with unilateral lumbosacral radiculopathy. Hong Kong Med J 2016;22:320-326.

Dragert K, Zehr EP. Bilateral neuromuscular plasticity from unilateral training of the ankle dorsiflexors. Exp Brain Res 2011;208:217-227.

Ehsani F, Nodehi-Moghadam A, Ghandali H, Ahmadizade Z. The com- 
parison of cross-education effect in young and elderly females from unilateral training of the elbow flexors. Med J Islam Repub Iran 2014;28:138.

Farthing JP. Cross-education of strength depends on limb dominance: implications for theory and application. Exerc Sport Sci Rev 2009;37: 179-187.

Farthing JP, Borowsky R, Chilibeck PD, Binsted G, Sarty GE. Neuro-physiological adaptations associated with cross-education of strength. Brain Topogr 2007;20:77-88.

Fernández-Cuevas I, Marins JC, Lastras JA, Gómez-Carmona PM, Cano SP, García-Concepción MÁ, Sillero-Quintana M. Classification of factors influencing the use of infrared thermography in humans: a review. Infrared Phys Technol 2015;71:28-55.

Fernández-Cuevas I, Sillero-Quintana M, Garcia-Concepcion MA, Ribot Serrano J, Gómez-Carmona PM, Bouzas Marins JC. Monitoring skin thermal response to training with infrared thermography. New Stud Athletics 2014;29:57-71.

Ferreira JJ, Mendonça LC, Nunes LA, Andrade Filho AC, Rebelatto JR, Salvini TF. Exercise-associated thermographic changes in young and elderly subjects. Ann Biomed Eng 2008;36:1420-1427.

Fimland MS, Helgerud J, Solstad GM, Iversen VM, Leivseth G, Hoff J. Neural adaptations underlying cross-education after unilateral strength training. Eur J Appl Physiol 2009;107:723-730.

Formenti D, Ludwig N, Gargano M, Gondola M, Dellerma N, Caumo A, Alberti G. Thermal imaging of exercise-associated skin temperature changes in trained and untrained female subjects. Ann Biomed Eng 2013;41:863-871.

Formenti D, Ludwig N, Trecroci A, Gargano M, Michielon G, Caumo A, Alberti G. Dynamics of thermographic skin temperature response during squat exercise at two different speeds. J Therm Biol 2016;59:5863.

Kenny GP, Webb P, Ducharme MB, Reardon FD, Jay O. Calorimetric measurement of postexercise net heat loss and residual body heat storage. Med Sci Sports Exerc 2008;40:1629-1636.

LaForgia J, Withers RT, Gore CJ. Effects of exercise intensity and duration on the excess post-exercise oxygen consumption. J Sports Sci 2006;24: 1247-1264.

Lee D, Park J, Lee S. Isometric contraction of an upper extremity and its effects on the contralateral lower extremity. J Phys Ther Sci 2014;26: 1707-1709.

Lee M, Carroll TJ. Cross education: possible mechanisms for the contralateral effects of unilateral resistance training. Sports Med 2007;37:1-14.

Lee M, Gandevia SC, Carroll TJ. Unilateral strength training increases voluntary activation of the opposite untrained limb. Clin Neurophysiol 2009;120:802-808.
Liu C, van Netten JJ, van Baal JG, Bus SA, van der Heijden F. Automatic detection of diabetic foot complications with infrared thermography by asymmetric analysis. J Biomed Opt 2015;20:26003.

Magalhães MF, Dibai-Filho AV, de Oliveira Guirro EC, Girasol CE, de Oliveira AK, Dias FR, Guirro RR. Evolution of skin temperature after the application of compressive forces on tendon, muscle and myofascial trigger point. PLoS One 2015;10:e0129034.

Magnus CR, Barss TS, Lanovaz JL, Farthing JP. Effects of cross-education on the muscle after a period of unilateral limb immobilization using a shoulder sling and swathe. J Appl Physiol (1985) 2010;109:1887-1894.

Marins JC, Fernández Cuevas I, Serrano JR, Sillero-Quintana M. Thermal response of the skin temperature on muscle and joint body areas after strength training by infrared thermography. Thermol int 2011;22:119120.

Merla A, Mattei PA, Di Donato L, Romani GL. Thermal imaging of cutaneous temperature modifications in runners during graded exercise. Ann Biomed Eng 2010;38:158-163.

Niu HH, Lui PW, Hu JS, Ting CK, Yin YC, Lo YL, Liu L, Lee TY. Thermal symmetry of skin temperature: normative data of normal subjects in Taiwan. Zhonghua Yi Xue Za Zhi (Taipei) 2001;64:459-468.

Okazaki K. Body temperature regulation during exercise training. In: Masaaki I, editor. Musculoskeletal disease associated with diabetes mellitus. Tokyo: Springer, 2016. p. 253-268.

Pincivero DM, Gandhi V, Timmons MK, Coelho AJ. Quadriceps femoris electromyogram during concentric, isometric and eccentric phases of fatiguing dynamic knee extensions. J Biomech 2006;39:246-254.

Rattey J, Martin PG, Kay D, Cannon J, Marino FE. Contralateral muscle fatigue in human quadriceps muscle: evidence for a centrally mediated fatigue response and cross-over effect. Pflugers Arch 2006;452:199-207.

Sariyildiz M, Karacan I, Rezvani A, Ergin O, Cidem M. Cross-education of muscle strength: cross-training effects are not confined to untrained contralateral homologous muscle. Scand J Med Sci Sports 2011;21: e359-364.

Taylor LW, Wilborn CD, Kreider RB, Willoughby DS. Effects of resistance exercise intensity on extracellular signal-regulated kinase $1 / 2$ mitogen-activated protein kinase activation in men. J Strength Cond Res 2012;26:599-607.

Van Loocke M, Lyons CG, Simms CK. Viscoelastic properties of passive skeletal muscle in compression: stress-relaxation behaviour and constitutive modelling. J Biomech 2008;41:1555-1566.

Velotta J, Weyer J, Ramirez A, Winstead J, Bahamonde R. Relationship between leg dominance tests and type of task. Port J Sports Sci 2011;11: 1035-1038.

Zult T, Howatson G, Kádár EE, Farthing JP, Hortobágyi T. Role of the mirror-neuron system in cross-education. Sports Med 2014;44:159-178. 